\title{
Cozinhando a céu aberto: relatos de vida de moradores de rua em Brasília
}

\author{
Pedro de Andrade Calil Jabur \\ Doutor em Sociologia (Universidade de Brasília) \\ Professor Adjunto da Universidade de Brasília \\ Brasília, Brasil \\ pedrojabur@gmail.com \\ BREITNER LUIZ TAVARES \\ Doutor em Sociologia (Universidade de Brasília) \\ Professor Adjunto da Universidade de Brasília \\ Brasília, Brasil \\ btavares02@gmail.com \\ JUSSARA MÁXIMO DA SILVA \\ Graduanda de Terapia Ocupacional (Universidade de Brasília) \\ Brasília, Brasil \\ YURE ROdRIGUES ARAúJo MARTINS \\ Graduando de Saúde Coletiva (Universidade de Brasília) \\ Brasília, Brasil
}

Resumo Este artigo apresenta uma pesquisa realizada em Brasília (DF) através de relatos de vida com pessoas/família que moram na rua e que preparam suas refeições em cozinhas e fogões improvisados nestes espaços. O sentido e o significado desta cozinha a céu aberto transformam o processo de alimentação em um dos mediadores centrais desta pesquisa e índice comunicativo e analítico importante para se entender a dinâmica de construção de identidades e sociabilidades desses sujeitos. A condição de vida na rua e todo um conjunto concreto e simbólico de frustrações e restrições inerentes a este contexto são, nesses cotidianos e trajetórias observadas e relatadas, objetos de construções de sentidos, que transformam, numa via de duplo sentido, estas cozinhas em abrigos e casas e, por isso, em espaços de reconhecimento e pertencimento.

Palavras chaves: Situação de rua; Alimentação; Cozinha; Histórias de vida; Pesquisa Qualitativa

\section{Introdução}

Z $\mathrm{STE}$ ARTIGO é resultado de uma pesquisa realizada durante três - meses entre 2013 e 2014, como parte do projeto de pesquisa Situações de rua: histórias de vida, vínculos e sociabilidade acerca da população em situação de rua em Braślia (DF) ${ }^{1}$. No trabalho de campo inicial, no

10 projeto de pesquisa Situações de rua: histórias de vida, vínculos e sociabilidade, que conta com financiamento do CNPq, foi submetido e aprovado pelo Comitê de Ética em Pesquisa em Seres Humanos da Faculdade de Saúde da Universidade de Brasília, em 10/07/2013, sob protocolo n. 330.731. 
processo de aproximação, observação, criação de vínculos e conversas preliminares, a alimentação se tornou um dos mediadores centrais desta pesquisa, a partir de um convite de um dos entrevistados para se sentar e dividir uma caneca de café.

Sem a intenção de apresentar um estudo quantitativo sobre o processo de alimentação da população de rua, realizamos entrevistas com dois indivíduos que especificamente preparavam o seu próprio alimento em fogueiras e fogões improvisados. Segundo o Censo da População em Situação de Rua (Prc-DF, 2011), realizado no Distrito Federal em 2011, apenas 1,4\% de um universo de quase três mil pessoas que vivem na rua preparam sua própria comida. Por isso, neste trabalho de pesquisa, o encontro com esses indivíduos aconteceu de maneira não planejada através do deslocamento em áreas centrais da região do Plano Piloto de Brasília.

Segundo Canesqui (1998), dentro da tradição dos estudos socioantropológicos brasileiros existe uma série de trabalhos, principalmente a partir da década de 1970, sobre o processo de alimentação das camadas populares da sociedade. Contudo, observa-se que não há qualquer tipo de menção à população de rua e seus hábitos alimentares, circunscrevendo a temática às classes de trabalhadores mais pobres, tanto do meio urbano como rural (Woortmann, 1978; Zaluar, 1985; Canesqui, 1987). Nesse sentido também, dentro dos estudos sobre população de rua, tanto na leitura de trabalhos mais antigos (Castelvecchi, 1982; Bursztyn e Araújo, 1997) como em pesquisas mais recentes (Escorel, 2000; Kasper, 2006; Frangella, 2009), a questão da alimentação é sempre exposta como um dos fatores estruturais e agravantes da condição miserável desta população, sem detalhar qualquer forma de arranjos e construções específicas no que tange à relação que esses sujeitos estabelecem com o processo de alimentação e, especificamente, por exemplo, com o preparo do próprio alimento.

Portanto, para além dos fatores restritivos em relação às condições econômicas e sociais dos entrevistados, tentaremos destacar como a comida e o seu respectivo preparo também representam uma maneira de relatar, concreta e simbolicamente, histórias, perspectivas e construir dentro de um contexto amplo novas formas de se viver na rua; outras situações de rua.

Como afirma Hauck-Lawson (1992), a comida, seu preparo, seu ritual e as memórias advindas deste ato social podem ser consideradas um importante canal comunicativo de expressão de significados, emoções, visões de mundo, identidades e sociabilidades. Como explica Dubar (2005), a trajetória de vida dos sujeitos está ligada à construção de identidades, como um lugar próprio - espaço de múltiplas histórias, tensões e polarizações, em que este se reconhece, ao mesmo tempo, como ser único e diferente dos outros. Neste sentido, a cozinha no meio da rua - improvisada; sujeita a intempéries, obstáculos, policiamento e discórdias, mas também espaço de construções e afirmações - é, sim, um ponto convergente das situações da e na rua desses entrevistados. Como explica um dos entrevistados, 'é sem muros, no céu aberto. Quem quiser chegar, chega que a gente vê como faz ou não faz'.

As entrevistas foram realizadas durante o dia, prioritariamente entre o meio dia e a parte da tarde e no final do dia, na tentativa de participar dos horários de refeição dos entrevistados. Em média, cada sujeito foi ouvido por cerca de quatro horas, divididas em três ou mais encontros, através de entrevistas anotadas com a anuência dos entrevistados através do Termo de Consentimento Livre e Esclarecido. Seus nomes verdadeiros não foram modificados sob o aceite dos próprios entrevistados.

\section{Situações de rua e relatos de vida: aproximações da pesquisa}

É somente em 2008, a partir da preparação do decreto que cria a Política Nacional para População em Situação de Rua, que a denominação População em Situação de Rua e sua respectiva sigla, PSR, passam a ser utilizadas tanto em documentos oficiais como em trabalhos acadêmicos. Neste documento, a noção de situação de rua se refere a um grupo populacional heterogêneo que possui em comum a pobreza extrema, os vínculos familiares fragilizados ou rompidos e a inexistência de moradia convencional regular. A utilização de espaços públicos e áreas degradadas como local de abrigo e de sustento, de forma temporária ou permanente, bem como unidades de serviços de acolhimento para pernoite temporário ou moradia provisória também se caracteriza como referência de definição dessa população (Brasil, 2008).

Embora, é perceptível um desenvolvimento no sentido de se elaborar uma definição menos censitária, não atribuindo, por exemplo, um único fator característico - ter ou não casa - é inegável, ainda, o curto alcance do termo quando se trata de definir as várias perspectivas sociais, culturais e econômicas acerca desta população.

A partir desta definição, Kasper (2006) chama atenção para o perigo de uma caracterização determinista da população de rua, da sua condição e do espaço que vive e, porque não, habita. Para o autor (2006), não seria possível afirmar que uma situação de extrema pobreza gera tão somente condições materiais e sociais de subsistência, ou mesmo situações (concretas e simbólicas) únicas, onde esta população - considerada como um grupo único e estanque em características, identidades, histórias de vida, motivações, estaria tão somente lutando por uma sobrevivência miserável.

Dentro desse conjunto de pré-concepções que tentam definir e, ao mesmo tempo, limitar a população de rua, as imagens ligadas à questão da comida possuem uma forte representação dentro do imaginário social no Brasil. De acordo com Zaluar (1985), a identidade de 
um indivíduo ou de seu grupo familiar passa, segundo as pesquisas realizadas pela autora, justamente pela posse ou não de comida. A categoria pobreza é demarcada, dentre outros fatores, segundo as próprias famílias de trabalhadores pobres estudadas, pelo acesso ou não à comida, pelo fato de se passar fome ou não e pelo acesso à ter carne na mesa todos os dias ou não.A figura do morto de fome, da falta ou da pouca comida, da mendicância por comida, a idéia da (ou de tirar a) barriga da miséria são concepções que estão ligadas diretamente à uma perspectiva sobre a vida na rua.

Além disso, como explica Da Matta (1997), tradicionalmente, no Brasil, o espaço social da casa sempre esteve ligada à imagem da comida, do seu preparo (dos temperos, do espaço da cozinha e da mulher), das farturas, dos convivas e da ritualística de se sentar à mesa para se comer em família. A rua, espaço de contraponto, é justamente o locus representativo do anonimato, da comida sem nome, do espaço da disputa (inclusive por comida) e por isso mesmo, o espaço da escassez, do desamparo e, porque não, da sua total falta. Nesse sentido, a figura do sujeito sujo, miserável, fedorento e anônimo, muitas vezes definhando-se em magreza, deambulando pelas ruas atrás de comida ou dinheiro se encontra no limite marginal de uma concepção de pobreza e fome dentro desse imaginário representativo.

Por isso mesmo, a imagem de um sujeito cozinhando a céu aberto - fazendo um convite para se aproximar, dividir um café, ou contribuir com algo para se engrossar a sopa; ou mesmo de uma mãe, colocando os filhos para se sentarem e comer todos juntos - possui uma série de significados e representações importantes para se entender, não uma única e estanque situação de rua, mas diversas possibilidades de situações de rua.

Claudia Girola (1996), antropóloga franco argentina, afirma que é preciso deixar de considerar a população de rua como uma espécie de retrato negativo da humanidade, analisada como um único conjunto indiferenciado e sempre a partir de suas perdas. Para a autora (1996), a escuta e a análise destas vidas devem tentar, a partir de uma atenção mais sensível, ultrapassar esse sentido primeiro de perdas, não para deixar de ouvi-las, mas para entrar em contato com outras palavras (justamente aquelas que não estão fixas) e, portanto, com outras construções de perdas e ganhos formadores de uma condição de realidade social e psíquica permeadas por faltas, mas que não deixa de ser humana.

A excepcionalidade concreta e simbólica de uma cozinha, e todo o seu ritual a céu aberto, permite compreender, por exemplo, que não se trata de uma única situação de rua, mas de diferentes vivências na e da rua. O tempo dedicado pelos indivíduos ao preparo de suas refeições, as formas de obtenção de alimentos, o espaço que esta cozinha ocupa na própria dinâmica concreta destas casas, os utensílios, seus propósitos, as histórias e lembranças constroem maneiras de compreender suas próprias vidas e condições.
Nesse sentido, a história de vida não constitui simplesmente um relato objetivo e exaustivo de eventos ocorridos na vida do narrador, nem exterior a eles, nem meramente um relato desinteressado, nem tão somente sobre um passado. Pelo contrário, é um relato dotado de uma afetividade particular e presente (concreta e emocionalmente) justamente porque é através dele que o indivíduo se conta e se reafirma como sujeito, dentro de determinados contextos.

Como explica Pais (2009), o relato biográfico revela-se como uma prática humana e como uma espécie de síntese de uma história social, onde as narrativas biográficas se constituem em um método que acaba por atribuir à subjetividade um valor de conhecimento que constitui ponto de partida para a compreensão da realidade social.

Por isso, neste trabalho, nossas observações e diálogos apresentados possuem uma relação bastante direta com a capacidade criadora e recriadora de significados e inventividades ligadas ao preparo da própria comida por esses sujeitos. O simbolismo envolvido no ato de comer, como expõe Montanari (2008), é ato, ao mesmo tempo, capaz de interligar memórias, desejos, significados, sociabilidades e rituais. As conversas e o preparo da comida se misturam em um relato de palavras e ações que - a partir tanto de ações e rememorações, estabelecem e constroem suas próprias realidades (Berger \& Luckmann, 1983).

Desta forma, nestas cozinhas sem portas que tivemos acesso - por convite ou por um misto de insistência e paciência, típicas do trabalho de campo, a relação desses sujeitos com o preparo do alimento serviu como uma espécie de índice comunicativo de uma série de outras representações, histórias e situações de vida na rua. Estas situações construídas e relatas estão constituídas justamente por esta multiplicidade de situações (de rua) vividas por estes sujeitos que acabam por elaborar uma temporalidade própria, aqui fortemente marcada por estas cozinhas. Estes itinerários de vida (e também de culinária, entendida como prática social) se desenham a partir de um certo número de acontecimentos estruturantes que marcam os relatos e que constituem o núcleo comum das formas possíveis de se apresentar e posteriormente analisar estas historias.

Estas cozinhas - as ações, concepções e sentidos construídos a partir delas - significam, como os próprios relatos explicitam, mais do que somente a possibilidade de alimentação (fator de extrema importância e necessidade em um contexto onde geralmente se come sem poder escolher que tipo de comida ou qual quantidade ou sem ter qualquer tipo de certeza quando se comerá novamente), mas também a tentativa, por parte desses indivíduos, de construir, concreta e simbolicamente, abrigos, que se tornam casas. Se, todavia, não possuem portas, elas representam a possibilidade de segurança, conforto e reconhecimento. 


\section{'Quando eu esquento, vira minha': contando histórias.}

Encontramos Ronaldo, 45 anos, em uma espécie de acampamento solitário com uma barraca de lona, em um descampado na região do Plano Piloto de Brasília. Sentado perto de uma fogueira, partiu dele a iniciativa de um diálogo ao nos oferecer para sentar e 'tomar um cafezinho, que ninguém é de ferro'. Bastante articulado, nos conta que está na rua há mais de 10 anos e chegou em Brasília em 2010, depois de passar por São Paulo, Minas Gerais e Tocantins.

Sou do mundo, mas gostei daqui e vou ficando. Aqui tem muita árvore sabe. É bonito. Às vezes, quando consigo deitar, fico pensando, olhando pro céu. Aqui deu vontade de ter casa pela primeira vez. Em São Paulo é viração toda hora (...) tem que correr de tudo e de todos, cheio de loucura e confusão. (Ronaldo, depoimento em Novembro de 2013)

Dentro da cabana montada, Ronaldo possui um fogão de acampamento, livros, revistas velhas e sacos plásticos, contendo um monte de roupas e cadernos, que segundo ele, fazem parte do livro que está escrevendo. Embora arrumada e limpa, ao ser questionado, se vive ali, naquele local, há bastante tempo, ele frisa o caráter transitório daquela casa e da vida nas ruas.

Na rua não tem muito dessa de vivo aqui ou vivo ali, endereço para correio, não (risos). Hoje eu tô aqui. Hoje, não, esse mês. A coisa vai ficando preta, eu pego minhas coisas e saio fora. Então hoje eu estou aqui, amanhã, não sei, depois, também não sei. Depois eu volto, depois eu vou. Não estou esperando nenhuma carta mesmo (...) então meu negócio é esse, recolho a parafernália e tchau e benção. Mas fico aqui perto na área por conta do mercado, onde arrumo meus ingredientes. (Ronaldo, depoimento em Novembro de 2013)

Ronaldo prepara o café com calma. O vento forte do dia acaba por atrapalhar, segundo ele, seu 'trabalho na cozinha'.

Gosto de cozinhar, sabe? Estou na rua porque eu quero. Porque nunca agüentei trabalhar para patrão e depois que minha mãe morreu, o pó, a bebida e o meu saco cheio me colocaram na rua. Mas estou aqui porque eu quero. Então não vou ficar aqui, igual os nóias de pedra, magrelo, mendigando comida. Tenho casa, cozinha, biblioteca e banheiro, na moita mais próxima (risos). (Ronaldo, depoimento em Novembro de 2013)

O café, segundo nos conta, é para 'agüentar até a hora da bóia', 'aquecer a barriga, enquanto não tem nada'. Misturado com um pouco de álcool, o gosto amargo da bebida acaba tomando conta daquela mistura oferecida. Parece ficar feliz, ao tomarmos a bebida e reclamar do gosto forte.

É forte, né? (risos). Não tem essa de café da manhã, almoço, jantar, sobremesa. Faço um café, quando tem. Se não é só pinga mesmo. Lá pela tarde faço um rango com o que consigo ou o que tem guardado aqui mesmo. Como e deixo um pouco para agüentar o frio (...) mas aqui não faz frio. Então como tudo e agüento até o outro dia. De vez em quando, ainda engano a fome, com um pedaço de pão ou fruta velha. (Ronaldo, depoimento em Novembro de 2013)

Sem questionarmos, logo se corrige,

Fome, fome, nunca passei não. De vez em quando dá um aperto, mas logo passa. É igual tu chegar em casa, abrir a geladeira e descobrir que sua madame esqueceu de fazer compras. Tu toma uma cervejinha, deita na cama e está tudo certo. (Ronaldo, depoimento em Novembro de 2013)

Ao ser questionado, como consegue os alimentos para a cozinha, Ronaldo explica um pouco do seu dia a dia.

Tem sempre uma graninha que entra, de pedir na porta do supermercado ali de cima. Ou tem sempre umas madames que perguntam se está precisando de comida. Compra fruta, pacote de bolacha (risos). O povo sempre acha que pobre gosta é de bolacha. Quando arrumo uma graninha, entro ali mesmo e compro umas batatas, um pedaço de carne de quarta (risos). É todo dia assim. Tem 'um truta' lá do supermercado, gerente, sempre arruma um saco, com couve, com beterraba, cenoura, que não tá nem estragada, mas não serve para mesa de patrão. Isso é o que salva. Passo lá, logo cedo, antes de abrir e já garanto. $\mathrm{O}$ cara acha maior graça que eu cozinho, então vou deixando ele achar graça e conseguindo o que dá para comer. A pinga nossa de cada dia, eu compro em outro canto, para não ficar dando bandeira de bebum e pé inchado. (Ronaldo, depoimento em Novembro de 2013)

Ronaldo, espontaneamente, explica o porquê de preferir cozinhar e o papel que isso representa para ele.

A gente vê esses nóias andando por aí, pedindo comida. Lá em São Paulo, tinha era de manada. Nego até arruma comida, mas fica nessa de ser humilhado, maltratado, tem dia que tem, tem dia que o carinha da lanchonete ou restaurante acorda com o pé errado e não arruma nada e aí fica como? Com a barriga na miséria! Tem nego que coloca veneno de rato, laxante só para maltratar. Eu peço comida também, mas é para fazer. Eu cozinho, como qualquer um cozinha dentro de casa. Pode não parecer, mas isso aqui é casa, é vida. Eu esquento do 
meu jeito, coloco o que tem e o que me dá na telha. É meu, saca? É comida mendigada, comprada com uns trocados, mas é meu. Quando eu esquento vira minha. (Ronaldo, depoimento em Novembro de 2013)

Convida-nos para voltar um outro dia, para comermos juntos. Antes de irmos embora, pede, para trazermos um saco de macarrão para 'ajudar a engrossar o caldo'.

Reencontramos Ronaldo, no meio da tarde, sentado junto ao fogão, com uma panela de ferro, já gasta e bastante enferrujada. Fica feliz, ao perceber que aceitamos o seu convite e que trouxemos o macarrão pedido. Quase como um chefe de cozinha, ele nos apresenta seu preparo.

Chegaram na hora. Achei que não viriam. Hoje teremos o de sempre. Sopa. Mas com o macarrão que vocês trouxeram, dá para disfarçar a água rala. Macarrão, cenoura e couve, um pouquinho de pinga para temperar (risos) e assim a gente esquenta o estômago e a alma. (Ronaldo, depoimento em Novembro de 2013)

Ronaldo parece bastante concentrado em preparar sua sopa. Pede para conversamos quando o 'rango estiver na mesa'. Despeja todo o pacote de macarrão e afirma, feliz, que, para ele, não tem miséria.

Tem comida, eu faço comida. Tem pouca comida, eu faço pouca comida, Tem muita comida, eu faço muita comida. Essa é a lei da minha cozinha. (Ronaldo, depoimento em Novembro de 2013)

Depois de pronta, nos oferece um prato, feito com o fundo de uma garrafa pet e busca na sua cabana, uma colher. Explica, que geralmente, quando não tem muita coisa, quebra um pacote de biscoito ou de pão dentro da sopa, para engrossar, mas que hoje não seria preciso por causa do macarrão.

Fica feliz ao elogiarmos a sopa. Explica, novamente, a importância, que tem para ele, o fato de poder cozinhar.

Aqui, o mundo é a minha casa. E toda a casa tem cozinha. Aqui é a minha. Fico feliz de poder sentar, parar a fazer a comida do jeito que eu quero e quanto eu quero. Não cozinho lá muito bem, mas uma panelada de sopa ou um arroz melequento, quem é que não sabe fazer? (Ronaldo, depoimento em Novembro de 2013)

Quando o questionamos, como aprendeu a cozinhar, Ronaldo explica.

Minha mãe sempre cozinhou lá em casa. Era só eu e ela. Nunca aprendi não. Foi na rua mesmo. Na necessidade. Desde que perdi tudo, fui me virando, com esse fogãozinho. A panela era lá de casa. Coisa da minha mãe. Herança (risos). A gente vai se virando. Tem dia, que chove e a comida ficar dura, o arroz sem gosto. Mas é assim. Então eu faço um arroz, ou sopa, ou misturo os dois (risos). Tem segredo não. É só por a panela no fogo e ir colocando o que tem e o que não tem. (Ronaldo, depoimento em Novembro de 2013)

Em um outro encontro, Ronaldo conta que, geralmente, come sozinho, mas que o preparo de comida no meio da rua sempre chama a atenção.

Minha cozinha, vocês já perceberam, é sem muros, no céu aberto. Quem quiser chegar, chega que a gente vê como faz ou não faz. Eu prefiro comer sozinho, mas de vez em quando, aparece uns aqui, pedindo um pouco. Ai eu aproveito para pedir para 'o cabra' ir ali em cima, arrumar mais umas coisas para engrossar o caldo. É bom poder sentar e trocar umas idéias. Mas tem umas figurinhas que já chegam na 'escrotidão'. Aí não rola, cara. Mando passear, ameaço dar com água quente, na cara. Mas os cara já estão tão louco que sai de manso daqui. (Ronaldo, depoimento em Novembro de 2013)

\section{E continua a explicação.}

Tem coisa ruim e tem coisa boa. Fogueirinha no meio da rua, também sempre chama atenção dos 'homi'. Agora, eles me conhecem. Chegam aqui, quando estou na labuta, eu já ofereço um café para limpar a barra. Eles nem sentam. Mas de primeira, era eu acender o fogão que logo vinha perguntando o que era, mandando apagar, chutando. Mas comida quente no meio da rua serve para arrumar namorada. Chega nóia, mas chega 'umas mulherzinha' também. Para mulher, não recuso não (risos). Só quando, acha que tem que mandar. Uma vez, chegou uma com dois moleques. Dei comida e tal. Mas já queria ir ficando, saca. A hora que eu acordasse, os moleques já iam estar me chamando de papai. Aí não rola. Comida quente, no meio dessa miséria, chama atenção. Ou o cara é doido que nem eu, ou é mulher, mãe de criança. Que cozinha na rua, só conheci assim. (Ronaldo, depoimento em Novembro de 2013)

De uma outra vez, Ronaldo responde um pouco mais sobre sua vida e essas amizades feitas em torno de sua cozinha.

Eu sempre fui sozinho mesmo. Nunca tive amigo, amigo mesmo, igual irmão. Tinha a minha mãe que resolveu morrer cedo. Meu pai, nunca nem vi e nem sei quem é. Na rua, aqui em Brasília, tenho até uns conhecidos. Mas é tudo miserável. Perambulando de um lado para o outro. Eu fico na minha. Tem dia que estou aqui, tem dia, que monto a barraca um pouco mais embaixo, lá para frente daquele mato. Não gosto muito de ficar dando trela para quem chega aqui, porque eu não sei o que o cara tá afim. Mas de vez em quando, é sempre bom, sentar aqui para conversar, puxar um fumo, encher 
a cara, trocar umas idéia sobre o mundo. Foi assim que eu vim parar aqui. O carinha chegou para mim lá em Patos de Minas e falou 'cê vai gostar de Brasília'. Deu a louca e vim. Converso mesmo, quando chega alguém. Eu mesmo não fico por ai perambulando, dando fita para quem não conheço não (...) Eu sou da rua, cara, mas tenho lá meu orgulho. Minha casinha, meus livros. Tomo banho quando dá para tomar banho, mas minha dignidade está aqui. Fogão, panela e comida quente na barriga. (Ronaldo, depoimento em Novembro de 2013)

\section{'Aqui é nossa casa e da cozinha, cuido eu': a história de uma família e sua casa na rua.}

Encontramos com Raimunda, seus dois filhos e seu marido morando em uma grande lona improvisada, numa região, quase de mata fechada, no Plano Piloto de Brasília. Ao passarmos de carro, nos chamou a atenção, uma família reunida em torno de uma fogueira. Bastante desconfiados - com receio de se tratar de funcionários do governo, querendo 'buscar seus filhos', ou 'derrubar a casa', demonstraram bastante receio e curiosidade quando nos apresentamos como pesquisadores e que gostaríamos de conhecer um pouco mais da vida deles.

Raimunda e seu marido, Firmino, logo responderam quase, ao mesmo tempo, em uma espécie de jogral que 'ali não havia nada para se conhecer não. É isso aqui e só'.

Aos poucos, explicando nossas intenções, Firmino nos pareceu mais calmo e falou para voltarmos outro dia ou outra hora, que, naquele momento, eles iam 'dar de comida aos meninos'.

No outro dia, na hora que marcamos previamente, Raimunda estava só com os filhos. O marido, que possui uma charrete de mão, estava recolhendo papelão e latinha pela asa norte, região de Brasília. Perguntou se não gostaríamos de esperá-lo, já que havíamos combinado e ficou bastante surpresa, quando respondemos que gostaríamos de conversar com ela mesmo.

Bastante introvertida e desconfiada, Raimunda, parece nervosa no início do nosso diálogo.

Mas vocês não são do governo, não né? Porque já vieram um povo aqui falando que se os meninos não tivessem na escola, iam tirar da gente. Que aqui a gente não pode ficar, que não sei mais o quê. (Raimunda, depoimento em Janeiro de 2014)

Seu espanto parece ser maior, quando explicamos para ela, nossas intenções de conhecer um pouco mais da vida dela e da família,

Vida da pobre né. Pode ver pela casa que conseguimos arrumar. Temos uma cozinha no meio do nada, desse matagal todo. (Raimunda, depoimento em Janeiro de 2014)

Aos poucos, porém, em uma fala pausada e sempre preocupada com seus filhos, de 5 e 7 anos, como nos informa, Raimunda nos conta um pouco sobre a vida daquela família.

A gente é do Maranhão, Eu e o Firmino. Os meninos nasceram na vida, sabe. Saímos de lá, faz 10 anos. Deu a louca no Firmino e saímos de lá para Bahia por conta de um trabalho dele, que não era nada. Fomos pro meio da rua. Os meninos nasceram por lá mesmo. Chegamos em Brasília, tem um ano só. Um colega nosso falou que aqui dava para ir agüentando por aqui, que tem trabalho de ajudante em construção. Mas até agora nada. Quero pôr os meninos na escola, mas não sei se vamos ficar. Todo dia, ele chega com uma idéia nova de ir embora de novo pro Maranhão. Então a gente não sabe. (Raimunda, depoimento em Janeiro de 2014)

Ainda inquieta com nossa presença, Raimunda, sentada em um papelão parece ter pressa para que possamos ir embora.

Sabe, já me acostumei em ir vivendo assim mesmo. De um lado para o outro. A gente leva o que dá para levar na carrocinha.Viemos a pé lá da Bahia. Mais de duas semanas de viagem, com os meninos. Não tem mais nada não. É só isso mesmo (...). O Firmino consegue vender os papelão e as latinha com um atravessador e a gente tem comida todo dia e vai juntando um pouco para poder voltar pro Maranhão. (Raimunda, depoimento em Janeiro de 2014)

Quando questionada sobre o que ela faz, Raimunda responde,

Eu fico cuidando dos menino aqui mesmo. Saio ali prá comprar uma comida ou o Firmino trás alguma coisa. Fartura não tem não, mas dá para a gente comer. Quando falta, pelo menos os menino come alguma coisa. (Raimunda, depoimento em Janeiro de 2014)

Parece ainda desconfiada, quando esclarecemos que gostaríamos justamente de conhecer como ela cuida da casa e do seu dia a dia.

Igual todo mundo, né. Daqui a pouco, tem um arroz que sobrou de ontem, eu vou esquentar pros menino comer. Eu como um pouco também. Mais para a tarde, quando o Firmino chega e que faço uma janta, melhor pro coitado comer. Ele passa o dia na rua e só come de noite mesmo. (Raimunda, depoimento em Janeiro de 2014)

Aos poucos, menos incomodada com nossa presença, Raimunda pede licença para poder esquentar a 
comida. Perguntamos se poderíamos ficar e Raimunda não faz objeções. Bastante atenciosa com os filhos, Raimunda volta da barraca com um fogão de acampamento e, com a ajuda do filho mais velho, acende uma pequena fogueira. Com duas panelas, Raimunda, esquenta o arroz e um caldo com batatas e um pouco de feijão. Parece envergonhada com o que tem para oferecer para seus filhos, mas brinca com a gente.

Estão servidos? Não é muito, não, mas é o que a gente tem. Esses dois comem a comida da mãe desde que nasceram e assim vai ser em quanto eu puder, se Deus quiser.Aqui, nunca passamos fome, não. Eu e meu marido já dormimos de barriga vazia, mas os meninos nunca. Isso é família. Da rua, mas é família. É o que eu falo sempre pro Firmino. (Raimunda, depoimento em Janeiro de 2014)

Esperamos cerca de três horas, enquanto seu marido chegava do trabalho. Neste tempo, Raimunda, quase obsessivamente, não parou de arrumar a casa, varrer um chão de terra impossível de ser totalmente limpo e dar instruções e tarefas para os filhos. O anúncio da chegada de Firmino aconteceu através do preparo da fogueira.

Já vou preparando o fogo, para quando ele chegar com a comida. Misturo com o que sobrou dos meninos e mais pra noitinha, sentamos aqui prá comer. Só não sei se vai dar para você também. (Raimunda, depoimento em Janeiro de 2014)

Esperamos Firmino chegar para nos apresentar novamente. Sua recepção foi efusiva, ao contrário do nosso primeiro encontro.

Quase não tenho ninguém para conversar. Podem aparecer para conversar. Se quiserem jantar com nós aqui, tem problema não. Traz um arroz, um feijão ou um macarrão. Se quiser trazer um pedaço de carne (risos). Aí vira janta de rico. A Raimunda é uma baita de uma cozinheira. (Firmino, depoimento em Janeiro de 2014)

O complemento de sua frase nos causou surpresa, e nos possibilitou relativizar nosso modelo pré-concebido até então, de uma família extremamente centralizada na figura do marido que, pelos relatos da esposa, ocupava todos os espaços e preocupações.

Cozinheira só não. Mulher e mãe dessa família aqui. E ela que tira a gente da rua, cuidando dessa bagunça e dos filhos. Ela é a controladora da cozinha aqui. (Firmino, depoimento em Janeiro de 2014)

Quando voltamos a encontrar Raimunda, trouxemos, como solicitado por Firmino, um saco de arroz e feijão. Entre feliz e envergonhada, Raimunda, mais solícita com nossa presença, explica
Sabe, faltar nunca faltou não. Mas muito obrigado, viu. Quando a gente tem um pouco mais, dá para fazer uma comidinha melhor, mais quentinha. Porque tem dias que o Firmino traz umas batatas murchas (risos), que tem que por água, para virar sopa. E é assim que é. Quando ele chegar, vai ficar feliz de ter convidado para a janta. Fica feio vocês aqui, me vendo cozinhar e não pode oferecer nada. Por que ninguém ajuda e pedir comida, isso não faço não. $\mathrm{O}$ que é que os meninos vão pensar dos pais. Aprender a mendigar logo cedo. (Raimunda, depoimento em Janeiro de 2014)

Raimunda é bastante articulada, mas também bastante introspectiva e de fala sempre desconfiada. Seu sentido de proteção daquela família passa pelo cuidado daquela casa e, principalmente, pelo fato de ter comida para fazer e poder colocar todo mundo para sentar juntos e comer.

A gente não tem casa, mas isso eu nunca digo perto dos meninos. Essa aqui é nossa casa e pronto. É o que tem. Eles sabem de nossa pobreza. Mas isso aqui é uma casa, tem 'coichão', tem panela, tem fogão e tem um lugar para sentar e comer igual gente, prato, copo e colher. Só porque estamos no meio da rua, não quer dizer que agora vamos ser animal, prá comer com a mão e do chão. Aqui é nossa casa e da cozinha cuido eu, sempre falo isso para o Firmino. (Raimunda, depoimento em Janeiro de 2014)

Bastante compenetrada, o acender da fogueira e o preparo das panelas e da comida indicam a chegada do Firmino, que hoje, levou um dos filhos, apesar da preocupação da Raimunda com os serviços do governo 'de ver o menino trabalhando ao invés de ir para a escola'. Cantarola baixo, enquanto cozinha, parece distante e pensativa. Interrompemos esses sonhos para perguntar sobre a sua cozinha e os seus sonhos que poderiam naquele momento ser compartilhados conosco. Raimunda conta,

Eu me distraio disso tudo, quando estou aqui cuidando da casa, ajudando o Firmino a pensar o que vai ser da vida, a criar os meninos. É o que a gente tem é o que é nosso. (Raimunda, depoimento em Janeiro de 2014)

A refeição partilhada com a família, quando da chegada de Firmino, é feita em volta da fogueira a partir dos pratos e talheres distribuídos por Raimunda. Tanto os meninos quanto Firmino parecem bastante felizes com nossa presença.

Muito bom ter gente aqui. Parece que até estamos em casa. Poucas vezes, eu chamo um companheiro, que está na pior, para comer aqui com a gente. De vez em quando dá problema, porque já quer trazer cachaça e aqui ninguém bebe. Eu não bebo, então fica estranho para eles e para gente aqui, perto dos meninos. Isso aqui parece uma 
casa e é assim que a gente gosta. (Raimunda, depoimento em Janeiro de 2014)

Após a refeição, enquanto, com um latão de água, que Firmino sempre traz depois de sua jornada de trabalho, Raimunda lava os pratos e talheres e guarda o resto da comida nas panelas, Firmino nos conta que está pensando em 'seguir a vida' de volta para o Maranhão.

Aqui dá até para arrumar comida, tem esse teto que sabe Deus até quando vão deixar em pé. Acho que está na hora de voltar para ter um sentido, sabe? Raimunda vive me falando para a gente voltar e eu insisto, mas tem jeito não. Os meninos estão crescendo e esse ano já perderam escola. Mais umas duas semanas e vamos. (Firmino, depoimento em Janeiro de 2014)

Ainda encontramos com Raimunda uma vez, que preparava o almoço daquele dia. Decididos a partir, ela nos confessa

Eu estou é aliviada. Essa coisa de ter casa no meio da rua, ficar no meio desse barro, dessa chuva. Os meninos sem escola, o Firmino só trazendo o que dá para o dia. Tá na hora mesmo de ter casa de verdade, de poder ter um canto e ter um lugar para poder cozinhar e chamar de nosso de verdade. (Raimunda, depoimento em Janeiro de 2014)

\section{A casa pela cozinha: discussão e considerações finais}

O convite de Ronaldo para um cafezinho ou mesmo a certa relutância e desconfiança de Raimunda em nos receber pela primeira vez, mas seu posterior convite para se juntar à mesa com a família, parecem não se encaixarem com muitas das dificuldades vividas em campo durante as pesquisas com indivíduos em situações de rua (Escorel, 2000; Frangella, 2009). Provavelmente, porque não se tratava, simplesmente, de estar na rua - pelada, miserável e anônima - mas simplesmente por estarmos nos aproximando de um espaço, construído por esses sujeitos, que representava muito mais uma casa do que simplesmente o espaço sem nome de uma rua ou canto qualquer.

Obviamente que as histórias de Ronaldo e Raimunda possuem diferenças analíticas, mas, é importante, novamente, destacar, que se assemelham, sob diversas perspectivas, a partir do espaço que a cozinha e o preparo da comida, ocupam em seus cotidianos. A rotina da busca ou da compra por alimentos, a possibilidade de se ter ou não convidados para se dividir a comida, o ritual da mesa, a criatividade e as construções econômicas no preparo do escasso alimento fazem parte de um movimento que constrói temporalidades, orientações e circunscreve esses sujeitos em um espaço que passa a ter propriedade, se não legal, simbólica. A expressão de Ronaldo, ao afirmar que quando cozinha o próprio alimento, este se torna seu, expressa esta propriedade construída a partir dessas cozinhas.

LeBlanc (2007), ao se referir ao contexto de precariedade vivido por sujeitos na rua, explica que uma das características que muitas vezes chama atenção dos pesquisadores e profissionais de instituições sociais e da área de saúde envolvidos com esta população é justamente a dificuldade em se construir relatos, histórias e mesmo informações que impliquem uma visão crítica do próprio sujeito sobre seu contexto. Nesse sentido, um outro ponto comum que se destaca a partir das falas dos entrevistados é o sentido reflexivo de suas perspectivas sobre seu cotidiano: o espaço da rua é percebido sob um olhar bastante crítico dentro do contexto de suas vidas e trajetórias.

A partir deste viés analítico - sem, contudo, como mencionamos, tentar extrapolar a análise dessas entrevistas e apresentar conclusões gerais a cerca da população de rua - pode-se pensar no espaço e na ação do preparo do alimento como uma dessas referências significantes da própria estruturação discursiva e da própria capacidade reflexiva e crítica que eles apresentam em suas falas. Como coloca Levi Strauss (2004), a cozinha e as diversas práticas a elas relacionadas podem ser entendidas como índices complexos que permitem a compreensão e os mecanismos sociais que estruturam sentidos e ações dos indivíduos. A busca pelos alimentos, sua divisão e estoque para posterior consumo, a construção de uma economia e de um ritual doméstico, seu preparo e elaboração fazem parte de atos significativos, artes de fazer, que como coloca Certeau (1994), representam a partir destas falas e fazeres ordinários, a estruturação de um campo semântico, que no dia a dia, constrói memórias, identidades e projetos e, porque não, a estrutura de um lar.

É nesse sentido que a tentativa de se construir um espaço diferente dessa imagem inóspita da rua por esses sujeitos passa, principalmente, por possuir uma cozinha e dela fazer uso para se diferenciar daquilo que Ronaldo chama de 'selva de nóias, chuva e policiais'. Idéia também presente na preocupação de Raimunda em apresentar condições para que sua família se reúna na hora da comida, sentados em círculo e comendo com pratos e talheres. Casas sem paredes e tetos, improvisadas e errantes, mas presente através de um fogão, de panelas herdadas, da fogueira acesa em dias de chuva e sol e no sentido simbólico que o fato, muitas vezes, de comprar, possuir e manipular a própria comida evidencia através de suas histórias.

Isso aqui é o que eu tenho, minha casa. Não tem essa de esculhambar, chegar aqui e ir entrando. Vocês, por exemplo, só chegaram por eu convidei. Aqui tem dono, lá fora é lá fora, selva de homens. Aqui dentro não. Aqui 
é meu, é minha comida, não é pedida, nem mendigada. (Ronaldo, depoimento em Novembro de 2013)

Nossa casa é o que a gente chama de casa. E eu cuido como se fosse casa. Tem dias que o Firmino insiste para eu não cozinhar, que dá muito trabalho. Mas aí ia fazer o quê? Pedir no meio da rua para os meninos aprenderem? Graças a deus, isto eu não faço não. Tem cozinha e por isso tem casa. (Raimunda, depoimento em Janeiro de 2014)

Embora, como explica Canesqui (1988), a utilização das classificações alimentares, dentro da tradição dos estudos socioantropológicos sobre comida, muitas vezes, aponta para o risco de um certo reducionismo sistêmico estruturalista, a diferenciação, explicitada nos relatos, entre a comida da rua, mendigada, fria, muitas vezes - como coloca Ronaldo - advinda de humilhações e a comida feita em casa, cozida e quente, fruto de um preparo próprio, de uma autoria, é bastante importante dentro das construções desses sujeitos.

Minha comida é especial porque sou eu que faço. Isso me tira um pouco dessa vida, sabe. Poder cozinhar, sentar, comer só, quieto, sem estar na dependência de ninguém. Se der vontade, ler alguma coisa, se não der, encher a cara mesmo. Eu não sou morador de rua, eu moro na rua. É diferente, sabe? (Ronaldo, depoimento em Novembro de 2013)

Embora relatado, neste trabalho, de uma maneira direta, o aceite ao convite de ambos os entrevistados para comermos juntos foi, de imediato, objeto de surpresa e dúvida. Afinal, como dividir a comida, objeto de escassez, transformado em imagem negativa e estereotipada das pessoas que vivem na rua? A percepção clara de que não estávamos na rua, mas entrando em suas casas - espaço privilegiado, como coloca Da Matta (1997), para o ritual da família e seus convidados em volta da mesa - nos possibilitou participar ativamente dessas histórias e compartilhar de sua comida e hospitalidade, até mesmo, como fazem as visitas em convites para almoços ou jantares, levar algo também para partilhar. Não estávamos dividindo uma comida da rua, escassa, mas uma refeição da casa, espaço privilegiado do partilhar, do convite à mesa (Da Matta, 1997). De uma suposta fartura, que se concretamente não existia, estava presente simbolicamente em seus relatos e no próprio ato de nos convidar à mesa.

A idéia de um dentro e fora no espaço vivido e construído por esses sujeitos é explicitamente relatado em suas histórias e afazeres. A rua está sempre lá fora, separado deste dentro, desta casa, que começa a partir de uma cozinha - espaço de chegada e de identidade de quem observa e se aproxima destas vidas.

O modelo familiar na casa de Raimunda é característico, daquele apresentado por Silva (2009), em pesquisa sobre hábitos e espaços da cozinha no interior do nordeste brasileiro. Enquanto Firmino se responsabiliza por trabalhar e comprar os alimentos, Raimunda parece, através de uma rotina vigilante e compenetrada, construir o espaço simbólico de uma casa, como aspecto do papel feminino dentro da família. A construção deste espaço moral da casa e da família, por Raimunda, é explicitado quando seu marido a define como 'controladora da cozinha', que em suas palavras, ultrapassa - a partir daí, o mero ato de cozinhar.

A casa, nesse sentido, não é simplesmente o correlato de um abrigo material, mas, como explica Woortmann (1978), um espaço de sociabilidades, contrapartida material da família que perpassa a religiosidade, o cuidado com a saúde e com os familiares e com a reprodução alimentar.

Aqui cuido eu, sabe. O Firmino cuida de ir lá ganhar o dinheiro dele. E dessa cozinha, dessa casa, dos meninos, quem coloca os pratos e a comida sou eu. Sempre foi assim. De vez em quando, de noite, falo para ele: ' Olha Firmino, amanhã não tem o que comer não'. Pois ele aí que acorda cedo e sempre volta com alguma coisa. Isso aqui é uma casa, porque tem pai que coloca o alimento e tem mãe que cuida e cozinha. (Raimunda, depoimento em Janeiro de 2014)

Para Ronaldo, o espaço construído de uma casa através da cozinha e da biblioteca é seu espaço de identificação, de memórias, onde se distingue da rua, dos 'nóias e 'pode ficar lendo e olhando para o céu, sem sustos'. É partir de sua cozinha, da comida preparada, do calor da fogueira montada, que Ronaldo toma posse de um espaço e pode, assim, como em uma casa, escolher seus convidados e demandar ajudas e necessidades. Dentro do nosso tempo de convivência durante a pesquisa, Ronaldo, bastante eloqüente e criativo em suas falas e opiniões, mencionou algumas vezes o livro que estava escrevendo, sem nunca, mesmo a pedidos, mostrá-lo ou se aprofundar no tema. Demonstrava, contudo, um certo orgulho, em exibir sua destreza através de suas 'invencionices na cozinha', como ele mesmo mencionava. Prefere fazer os caldos e as sopas 'para temperar com um pouco de bebida', assim como fez com o café quando nos serviu.

Meu cardápio é mais sopa porque jogo tudo dentro da água quente e deixo amolecer. Faço uma misturada e assim não força os dentes. Mas é coisa de chefe de cozinha. Tem umas invencionices na cozinha que rio sozinho quando fica pronta. Já comeu sopa com bolacha? Com couve, batata e bolacha? Sopa com pedra para engrossar o caldo? Faço sopa de tudo, só jogar um pouco de pinga e ta tudo certo. Dia desses tinha tomate e alface só. Coloquei na água, ficou uma gororoba, apaguei o fogo e corri no supermercado. Tinha uma dona lá que me deu umas duas barras de chocolate. Sabe o que 
eu fiz? Taquei na sopa. Precisa de ver, sopa de chocolate com tomate e alface. Criação minha! (Ronaldo, depoimento em Novembro de 2013)

Em um trabalho sobre a antropologia da alimentação, Farb e Armegalos (1980), destacam que a palavra companhia, derivada do francês e do latim, significa justamente aquele que come o pão (pain) com os outros. Esta comida preparada ao ar livre resulta neste trabalho de construir companhias, relações e perspectivas futuras.

A distinção proposta por Hannah Arendt (2010) entre trabalho e labor auxilia na análise do caráter ativo e simbólico que o preparo e o espaço desta cozinha/ casa/família possuem na vida destacada desses dois indivíduos. Esta comida, ao se tornar uma espécie de ponto central e excepcional em relação ao contexto de vida na rua se reveste, ao mesmo tempo, de um caráter de trabalho - relacionado à uma condição de existência e sobrevivência; mas também se torna labor, a partir de uma produtividade (simbólica) bastante própria. A comida preparada em suas respectivas 'cozinhas sem paredes', fruto muitas vezes de alimentos pedidos e mendigados, de relações construídas na rua e, principalmente, da escassez de recursos financeiros e materiais se transformam - ao serem preparados, esquentados em fogão próprio, divididos entre a família 'com copos e pratos de verdade', como reforça Raimunda, ou entre companheiros ocasionais - em comida própria, de casa, fruto, ao mesmo tempo, de trabalho e labor. É, portanto, transformado em posse, identidade (no sentido até mesmo de diferenciação perante outros indivíduos em situação de rua) e histórias para se contar, em um contexto, muitas vezes, vivido a partir somente de perdas e silêncios.

\section{Referências}

ARENDT, Hannah. A Condição Humana. $8^{\mathrm{a}}$ ed. Rio de Janeiro: Forense Universitária, 2010.

BERGER, Peter \& LUCKMANN, Thomas. A construção social da realidade. $5^{\circ}$ ed. Petrópolis: Editora Vozes, 1983.

BRASIL . Política Nacional para Inclusão Social da População de Rua. Governo Federal: Ministério do Desenvolvimento Social (MDS), Brasília-DF, 2008.

BURSZTYN, M; ARAÚJO, C.H. Da utopia à exclusão. Vivendo nas ruas em Brasília. Rio de Janeiro: Garamond,
Brasília: Codeplan, 1997.

CANESQUI, A.M. Organização e realização do consumo alimentar cotidiano. Campinas, Departamento de Medicina Preventiva e Social da Faculdade de Ciências Médicas da UNICAMP, 1987.

. Antropologia e alimentação. Revista Saúde Pública, São Paulo, v. 22, n. 3, Junho 1988 .

CASTELVECCHI, G. Quantas vidas eu tivesse, tantas vidas eu daria! São Paulo: Edições Paulinas, 1985.

CERTEAU, Michel de. A invenção do cotidiano: 1, Artes de fazer. Petrópolis:Vozes, 1994.

DA MATTA, Roberto. O que faz o brasil, Brasil? Rio de Janeiro: Rocco, 1997.

DUBAR, C. Usages sociaux et sociologiques de la notion d'identité. Éducation Permanente. no 128, pp. 37-43, 2005.

ESCOREL, S. Vidas ao leú. Rio de Janeiro: Fiocruz, 2000.

FARB, P. \& G. ARMEGALOS. Consuming Passions: The Anthropology of Eating. Boston: Houghton Mifflin, 1980.

FRANGELLA, Simone M. Corpos urbanos errantes: uma etnografia da corporalidade de moradores de rua em São Paulo. São Paulo: Anablume, Fapesp, 2009.

GIROLA, Claudia M. Recontrer des personnes sans abri. Une anthropologie réflexive. In: Politix. Vol. $9, \mathrm{n}^{\circ} 34$. Deuxième trimestre, p: 87-98, 1996.

HAUCK-LAWSON, Annie. Hearing the Food Voice: An Epiphany for a Researcher. Digest - An Interdisciplinary Study of Food and Foodways, v. 12, n. 1-2, p. 6-7, 1992.

KASPER, Christian Pierre. Habitar a rua. Campinas, 2006. Tese de Doutorado - Ciências Sociais - Universidade Estadual de Campinas (Unicamp).

LE BLANC, G. Vidas ordinárias Vidas precárias: Sobre la exclusión social. Buenos Aires: Nova Visión, 2007.

LÉVI-STRAUSS, C. O cru e o cozido. São Paulo, CosacNaify, 2004.

MONTANARI, Massimo. Comida como cultura. São Paulo: Editora SENAC São Paulo, 2008.

PAIS, José Machado. Sociologia da vida cotidiana - Teorias, métodos e estudos de caso. $4^{\circ}$ edição. Lisboa: ICS, 2009.

PRC - DF - Projeto Renovando a Cidadania - Distrito Federal. Pesquisa sobre a população em Situação de Rua do Distrito Federal, Brasília, 2011.

SILVA, Marilu Albano. Cozinha: espaço de relações sociais. Revista Iluminuras. v. 10, n. $23,2009$.

WOORTMANN, K. Hábitos e ideologias aumentares em grupos de baixa renda: relatório final de pesquisa. Série Antropológica 20. Brasília. Universidade de Brasília, 1978.

ZALUAR,Alba. A Máquina e a Revolta: as organizações populares e o significado da pobreza. São Paulo: Brasiliense, 1985. 


\title{
Cooking in the open: life stories of homeless people in Brasilia
}

\begin{abstract}
This article shows a research done in Brasilia (DF) with life stories of homeless people/families that make their own food in improvised stoves and kitchens in those places. The meaning and significance of these outdoor improvised kitchens change the feeding process as one of the key mediators and as a communicative and analytic index very important to get to know the dynamic of building an identity and social abilities of this subjects. The condition of living in the streets with all the concrete and symbolic frustrations and restrictions of this context, in these daily events and trajectories seen and reported, are building objects of meaning, that transform, in a two way sense, these kitchens in shelters and homes and, by that, in places of recognition and belonging.
\end{abstract}

KeyWords: Homeless; Feeding; Kitchens; Life Stories; Qualitative Research

\section{Cocinar a cielo abierto: historias de vida de las personas sin hogar en Brasilia}

\section{Resumen}

Este artículo presenta una investigación realizada em Brasilia (DF) por medio de relatos de vida con personas/familias que viven en las calles y preparan sus alimentos en cocinas y estufas improvisadas en estos espacios. El sentido y significado de estas cocinas a cielo abierto transforman el proceso de la alimentación en uno de los mediadores clave de esta investigación, así como un índice comunicativo y analítico importante para se entender la dinámica de la construcción de identidades y sociabilidad de estos sujetos. La condición de vida de calle y todo un conjunto concreto y simbólico de frustraciones y restricciones pertinentes a este contexto, eventos cotidianos y trayectorias son observadas y relatadas, objetos de construcción de sentidos, que transforman, en un sentido bidireccional, estas cocinas en refugios y casas y, por esto, en espacios de reconocimiento y pertenencia.

Palabras Clave: Personas sin hogar; Alimentación; Cocinas; Historias de vida; Investigación cualitativa.

Dara de recebimento: 26 - $01-2015$

Data de aprovação: 22- 09 - 2015 